\title{
La Alameda de Hércules de Sevilla: De jardín a espacio público como soporte de la sociedad y del patrimonio contemporáneo
}

\section{Carolina Quilodrán Rubio $^{a}$, Juan Andrés Rodríguez Lora ${ }^{b}$, Javier Ostos Prieto ${ }^{\mathrm{c}}$ y María Teresa Pérez Cano ${ }^{\mathrm{d}}$}

${ }^{a}$ Facultad de Arquitectura y Urbanismo Universidad de Chile, 8331051, Santiago. cquilodran@uchilefau.cl, ${ }^{b}$ Escuela Técnica Superior de Arquitectura de la Universidad de Sevilla, Av. Reina Mercedes, 2, 41012, Sevilla. jrodriguez91@us.es, ${ }^{c}$ Escuela Técnica Superior de Arquitectura de la Universidad de Sevilla, Av. Reina Mercedes, 2, 41012, Sevilla. fostos1@us.es, ${ }^{\mathrm{d}}$ Escuela Técnica Superior de Arquitectura de la Universidad de Sevilla, Av. Reina Mercedes, 2, 41012, Sevilla. tpcano@us.es

\begin{abstract}
Resumen
La protección del patrimonio ha caminado desde la mirada detenida de la pieza arquitectónica singular, al espacio urbano de la ciudad. El concepto de patrimonio ha ido evolucionando a lo largo de los siglos XX y XXI. Sin embargo, salvo la excepción de la tipología de Bien de Interés Cultural clasificado como Jardín Histórico de las leyes de patrimonio vigentes, el espacio público ha tenido hasta la fecha poco reconocimiento y aún más escasa protección, tanto desde la administración cultural como la urbanística. Éste no ocupa la posición relevante que adquiere en la ciudad actual vinculada en su crecimiento a los postulados del Movimiento Moderno.

La presente investigación aborda el caso sevillano de la Alameda de Hércules. Espacio público de gran relevancia, cuyo germen tiene su origen en 1574 cuando el asistente Francisco Zapata de Cisneros, Conde de Barajas, desecando un brazo del río Guadalquivir, generará una de las tipologías más singulares y que más han influido en el diseño de otras ciudades españolas y americanas: las alamedas.

La propuesta reflexionará en torno a su protección y consecuencias, así como a la adaptación y evolución de un espacio histórico destinado doblemente a un habitante local y a otro mucho más globalizado.
\end{abstract}

Palabras clave: alamedas, espacio público, patrimonio contemporáneo, protección del planeamiento, Sevilla, transferencias tipológicas.

\begin{abstract}
The heritage protection has developed from a careful look at the unique architectural piece, to an urban area of the city. The concept of heritage has changed throughout the $20^{\text {th }}$ and $21^{\text {st }}$ centuries. However, with the exception of the typology of a Cultural Interest Property classified as a Historical Garden under current heritage laws, the urban public space has so far received little recognition and even less protection from both the cultural and urban administration. This did not occupy the relevant position it acquires in the current city linked in its growth to the postulates of the Modern Movement.

The current research deals with the case of the "Alameda de Hércules" in Seville. Public space of great relevance, whose germ originates in 1574 when the assistant Francisco Zapata de Cisneros, Count of Barajas, draining a branch of the Guadalquivir River, would generate one of the most singular typologies of public space and which has most influenced the design of other Spanish and American cities: the avenues.

The proposal will reflect on their protection and the consequences of this, as well as on the adaptation and evolution of a historical space destined both for a type of local inhabitant and to another much more globalised one.
\end{abstract}

Keywords: alameda, public space, contemporary heritage, urban planning protection, Seville, typological transfers. 


\section{Introducción}

A lo largo de la historia, en las ciudades europeas han existido distintos ámbitos de convivencia y sociabilidad. Si bien en Roma eran el foro y los edificios de espectáculos, en las ciudades medievales los espacios abiertos intramuros eran limitados, ya que las murallas eran una frontera que condicionaba la expansión y crecimiento de la urbe. De este modo, en la ciudad amurallada destacaban dentro de su configuración espacial al menos los siguiente elementos, a saber: las calles, los edificios, iglesias y conventos, mercados, jardines privados y la propia muralla.

En este contexto, cabría destacar que los espacios de convivencia en sus orígenes tenían un carácter privado y eran de uso exlusivo de la alta sociedad. Entonces ¿cuál fue el objetivo de la creación de la Alameda de Hércules de Sevilla? Su concepción en el siglo XVI en un espacio intramuros de la ciudad permitiría experimentar, sobre todo, un cambio en la rígida trama urbana medieval con un nuevo concepto de espacialidad y regularidad en el interior de una ciudad amurallada. Así, el saneamiento urbano realizado por el Conde de Barajas en 1574 en el sector denominado Laguna-La Feria, no sólo serviría para transformar un lugar constamente indundado, sino que desde ese momento adquiriría una vocación urbana: un espacio arbolado con álamos, una alameda para el disfrute de la sociedad. La alameda tenía una forma alargada configurada por hileras de árboles a las cuales se le añadirían elementos ornamentales tales como fuentes, bancos y esculturas, entre otros (León, 2000).

Paralelamente, en otras ciudades surgirán otros elementos también considerados espacios públicos: las plazas mayores, pero carentes de vegetación. A estos se añadirán miradores y paseos arbolados que también adquieren importancia en la escena urbana, tanto intramuros como extramuros.

La aparición de esta nueva tipología de espacio público arbolado se convertiría en un referente para otros lugares influenciados por el caso sevillano, Así sucederá con la Alameda de San Pablo de Écija y en ciudades americanas de nueva fundación como la Alameda de Ciudad de México, 1592 o la Alameda de los Descalzos de Lima en 1611.

\section{Objetivos}

El objetivo principal de la investigación es reflexionar a partir del estudio histórico de la Alameda de Hércules de Sevilla y su evolución, en la influencia que ésta tendrá en otras alamedas a nivel nacional e internacional y abogar por un grado de protección acorde a los valores patrimoniales que la misma tiene. Desvelar las claves de su pervivencia, un espacio público cambiante, numerosas veces adaptado a las necesidades de las sociedades que han ido surgiendo a lo largo de la historia.

Al mismo tiempo, se pretende abundar en mayor medida en el reconocimiento como espacio tipológico de sociabilización de referencia en el panorama internacional, especialmente en el contexto de la Sevilla en que surge, como una expresión de su época y que ha trascendido hasta la actualidad.

\section{Metodología}

Para llevar a cabo los objetivos marcados, se realiza una revisión bibliográfica de publicaciones especializadas en las alamedas en general y en la de Hércules en particular, en entrevistas con investigadores especializados en espacios públicos, así como, se realiza una revisión de las herramientas legales de protección. De modo que se consideran tanto los espacios públicos declarados como bienes patrimoniales, bien sea como Bien de Interés Cultural o porque estén incluidos en el Catálogo General del Patrimonio Histórico Andaluz en la escala autonómica (Junta de Andalucía, 2019), además de en los catálogos del Plan General de Ordenación Urbanística de Sevilla y del Plan Especial de Protección del Sector 1 del Conjunto Histórico de Sevilla, denominado "San Gil-Alameda" (Ayuntamiento de Sevilla, 2002).

\section{Un acercamiento a la Alameda de Hércules}

De acuerdo con los aportes realizados por los autores Albardonedo, Collantes de Terán Sánchez y Vigil-Escalera (entrevistas en octubre de 2019) en los encuentros con los mismos, a propósito de las alamedas, se desprende lo siguiente: a partir del siglo XVI se puede definir como un tipo urbano cuyo objetivo fue acondicionar un espacio vacío, 
desecar un terreno inundable o recuperar un terreno abandonado. Por otro lado, destaca el que contara con una composición lineal de los árboles -este carácter alineado servía para ejercicio atlético- y un remate circoagonal. Además, en el siglo XV fue un espacio donde los caballeros se preparaban para la actividad militar y, finalmente, las alamedas no son lo mismo que los parques y jardines, considerando en el primer caso su espacio delimitado y cerrado y en el segundo, alberga la incorporación de otras masas vegetales: arbolado, parterres y arbustos.

Igualmente, se podrían dar otras claves a través de las cuáles ahondar en su forma y emplazamiento: ¿de dónde viene la forma longitudinal y el remate circoagonal que adquieron algunas alamedas?

Chueca Goitia (Chueca, 1954) expresa, por ejemplo, para el caso de El Prado de Madrid que uno de los principales problemas de quienes trazaron el paseo, José de Hermosilla y luego Ventura Rodríguez, sería algo eminentemente barroco que era reducir a una sola unidad un gran conjunto. En este caso, se contaba con un espacio longitudinal muy alargado al cual se le dispuso una forma circoagonal que terminaba en sus extremos en dos semicírculos y en el centro de éste se emplazaban dos fuentes enfrentadas de carácter simétrico y con relación a una central que era el punto medio de esta composición unitaria (Fig. 1).

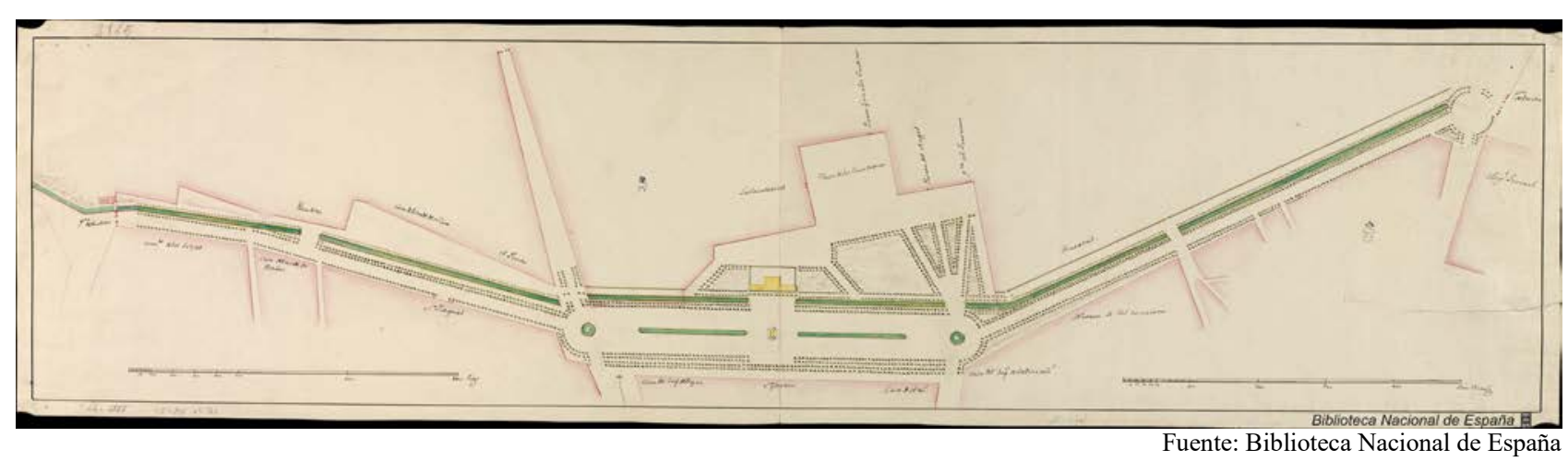

Fig. 1 Plano de los paseos del Prado, Recoletos y Atocha de Madrid (1767)

Además, habría que destacar la importancia de la exhibición pública dentro de la burguesía urbana, principalmente, entre los siglos XVI y XVIII. Así mismo, su creación responde, entre otros objetivos, a la ampliación de las dotaciones de agua corriente en las ciudades y al ensanche de espacios urbanos en los que se dotan de arbolado.

De esta manera, para la conformación del paseo, un elemento importante fue la introducción del árbol en el espacio público considerado hoy como un bien común, probablemente debido a la climatología sevillana. Es así como las alamedas de España y de los territorios españoles en América fueron experiencias pioneras en este campo. Estos lugares con árboles se plantaron originalmente con álamos negros o blancos (Paya, 2014). Según Emilio José Luque Azcona (Luque, 2015) fue "en el siglo XVIII, y especialmente durante su segunda mitad, cuando se conformaron numerosas alamedas y paseos en ciudades de diferentes puntos de la América española”.

Con respecto a lo anterior, Concepción Lopezosa Aparicio (Lopezosa, 2016) fundamenta que "los paseos públicos para el esparcimiento y recreación de los ciudadanos fueron realidades ligadas a las principales ciudades españolas desde finales del siglo XVI convirtiéndose en referentes significativos de las urbes". Así sería que la Alameda de Hércules, el Paseo El Prado de Madrid o la Alameda de México serían ejemplos concretos de la política urbana de Felipe II (Lopezosa, 2016). Esta transferencia tipológica se daría en el paseo de la Alameda de los Descalzos de Lima en Perú realizado por el virrey Marqués de Montesclaros, antiguo asistente de Sevilla (Figs. 2 y 3 ).

A lo anterior, María Antonia Durán Montero (Durán, 1985) añadiría una importante función a Juan de Mendoza y Luna, marqués de Montesclaros, Virrey de Nueva España y, posteriormente, Virrey del Perú, quién ya conocía la de Sevilla y que con su estancia posterior en México le habría permitido el primer intento de alameda americana.

El proyecto de la Alameda de Hércules de Sevilla según Antonio Albardonedo Freire (Albardonero, 1998) "tenía una extensión de tres kilómetros e implicaba la regeneración de una gran zona degradada, así como la mejora de la infraestructura de abastecimiento de agua en muchas collaciones de la ciudad". 


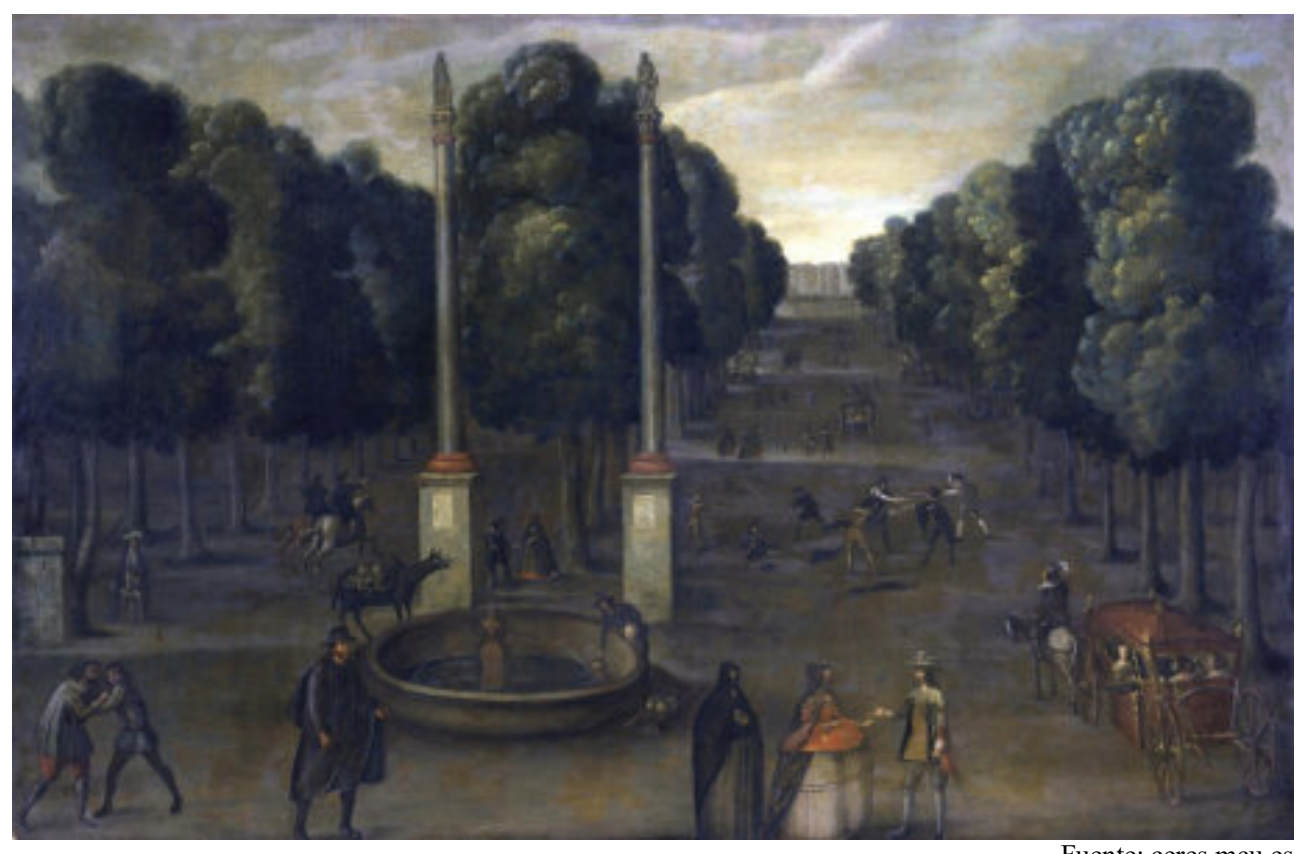

Fig. 2 Alameda de Hércules de Sevilla, España (1574)



Fig. 3 Plan de la Ville de Lima, au Perou (s. XVIII)

Siguiendo lo expuesto por Albardonedo (Albardonero, 1998) sobre el proceso de recuperar un espacio degradado como era La Laguna es necesario, igualmente, considerar que su inserción en el tejido urbano de Sevilla permitió dar un concepto de regularidad espacial, tal como lo planteó Miguel Torres García (Torres, 2019) explicando que la Alameda, al igual que la Giralda, intentaba imponer un orden humanista incorporando ritmo y perspectiva en una trama urbana heredada de la Edad Media. Es así como a partir del siglo XVIII la ciudad asistirá a la extensión de los espacios públicos con el objetivo de fomentar el aprovechamiento de la naturaleza y, a su vez, a la creación de extensiones verdes para el recreo o la reflexión erudita (Ollero, 2015). Sonsoles Nieto Caldeiro (Nieto, 1991) también considera que se buscaba el ensalzamiento de la naturaleza a través de la creación de alamedas, acercando el campo cultivado y aristocrátio a determinadas esferas sociales. De esta manera, su ubicación dentro de la trama histórica, en el extremo noroeste de la ciudad de Sevilla, alejada de la centralidad y los ejes de circulación, le daría a esta área degradada una recalificación del espacio circundante. Recurriendo a la cartografía histórica, en el caso del plano de Olavide del año 1771, se puede observar cómo el único espacio libre para el recreo social de destacada entidad por su tamaño es la Alameda de Hércules, antes de las aperturas de otros espacios significativos en la trama de la ciudad heredada (Fig. 4).

En 1764 se inician las nuevas obras en la Alameda que suponía la plantación de 1.600 álamos, el aumento del número de fuentes y la disposición de dos columnas en el extremo norte de este espacio. De este modo, la alameda quedaba configurada como una estructura geométrica (Vioque et al., 1987) acotada por al menos tres hileras de árboles. 


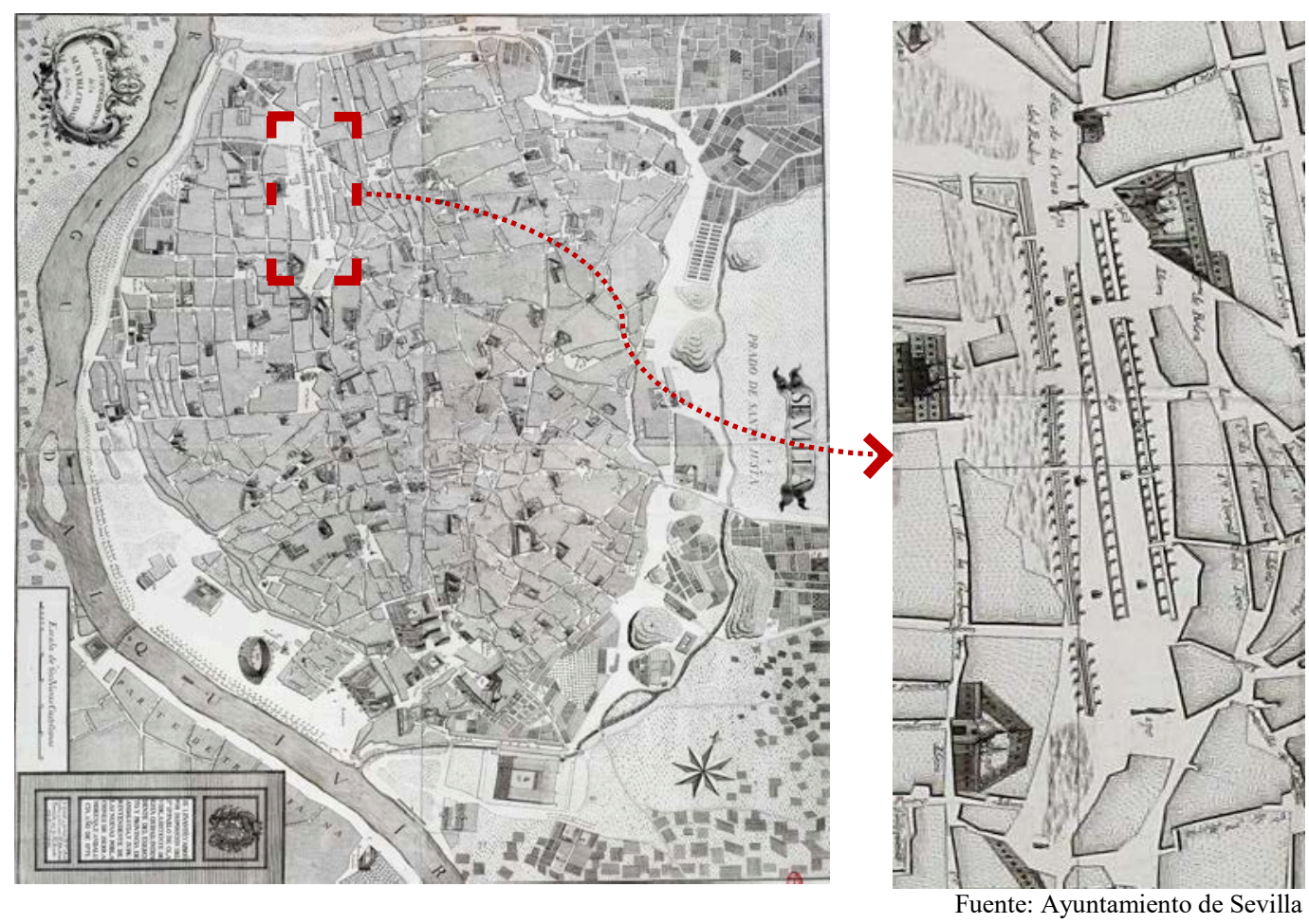

Fig. 4 Planta de la Alameda de Hércules (derecha) en el Plano de Olavide (1771)

Miguel Torres García (Torres, 2019) realiza una importante reflexión sobre la Alameda de Hércules en términos de su representación iconográfica, considerando este espacio y su relación con el paisaje y el río: "en el azulejo de Osuna en Sevilla se abandona la vista perspectiva para hacer una representación corográfica en un estilo más analítico [...] El aspecto más relevante reside en la relación que se establece entre la Alameda de Hércules y el paisaje visible desde la orilla del río. En esta imagen, los edificios circundantes, y de forma más importante las murallas, se eliminan para sugerir una integración completa de la alameda con el sistema de paseos arbolados en la margen del río que aparecen en el plano de Olavide". El autor se refiere a la representación de la alameda que aparece en el zócalo de azulejos que se encuentra en el claustro principal del convento de la Encarnación en el municipio sevillano de Osuna. La escena nos muestra la vida cotidiana de la ciudad con personajes que transitan a pie y a caballo, el acto público que se realizaba en la Alameda de Hércules, recogiendo los elementos que componen este lugar: un espacio longitudinal que remata en dos columnas, un arbolado lineal y las aguas que lo alimentan en su entorno, un espacio central con fuentes y bancos.

\section{La protección de la Alameda de Hércules}

Una vez señaladala importancia de la Alameda de Hércules de Sevilla, cabría plantearse cuál es el nivel de reconocimiento patrimonial que ésta tiene ya sea desde la administración cultural (nacional o autonómica) o de la urbanística (municipal). Si atendemos a la protección que a nivel nacional y autonómico se le otorga a los bienes culturales, podríamos destacar dos de ellos: el primero, el de Bien de Interés Cultural, conocido como BIC, como máxima protección (en el que entrarían los bienes de diversa naturaleza y bajo diferentes figuras. La de Jardín Histórico es la comúnmente utilizada en estos espacios libres) y el segundo, el nivel de Bien inscrito en el Catálogo General del Patrimonio Histórico Andaluz. Ambas figuras recogidas en la Ley 14/2007 del Patrimonio Histórico de Andalucía y la de BIC también incluida en la Ley 16/1985 del Patrimonio Histórico Español.

En el caso de Andalucía son varias las Alamedas que se encuentran inscritas en dicho Catálogo General, tales como la Alameda Apodaca y Marqués de Comillas en Cádiz o la Alameda de Capuchinos de Jaén, entre otras, no figurando la de Sevilla. Así lo atestigua el plano de la Gerencia de Urbanismo de la ciudad, donde se representan los Bienes Patrimoniales declarados por el gobierno andaluz, en el cual se evidencia que la Alameda de Hércules, a nivel autonómico, no encontraría ningún tipo de reconocimiento o protección (Fig. 5). 
BIC con entorno declarado

BIC sin entorno declarado

BIC sin entorno

Bien inscrito en el Catálogo General

- Conjunto Histórico Declarado

- Alameda de Hércules

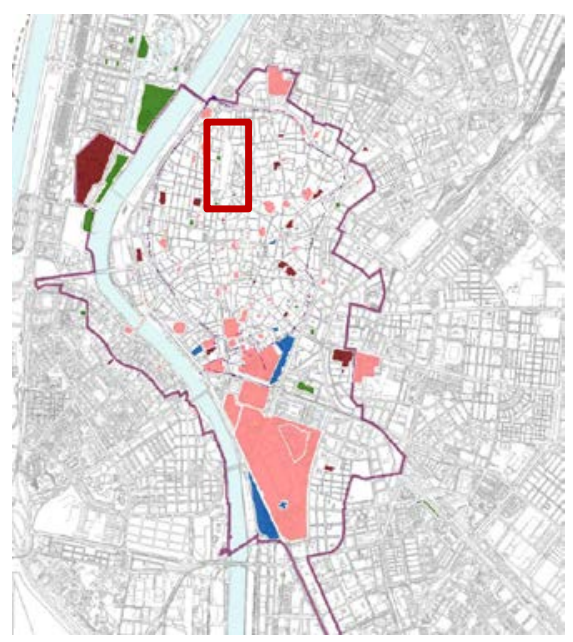

Fuente: Gerencia de Urbanismo de Sevilla

Fig. 5 Reconocimiento y protección de la Alameda de Hércules a nivel autonómico

Si nos centramos en la escala municipal, habría que señalar que la Alameda se encuentra incluida en el Catálogo de Protección del Plan Especial del Sector 1, denominado "San Gil-Alameda", del Conjunto Histórico de Sevilla que tuvo su aprobación definitiva en el año 2002. Atendiendo a su ficha de catalogación se puede observar que se encuentra denominada como Espacio Público, donde únicamente se protegen como elementos de valor: las columnas, el quiosco y el tipo de arbolado.

Esta ausencia de protección efectiva, facilitó que en el año 2008, fuera objeto de una completa remodelación con una intervención contemporánea, a través de la propuesta ganadora del concurso de José Antonio Martínez Lapeña y Elías Torres que vendría a unificar todo el espacio bajo un mismo pavimento color albero e intensificando la linealidad característica de la Alameda. Dicha intervención, criticada por unos y alavadas por otros, vendría a dar soporte a las nuevas realidades sociales y de uso de la Alameda de Hércules de manera intensiva, erigiéndose como uno de los espacios públicos más característicos y concurridos, así como por su considerable entidad, dentro de la urbe heredada (Fig. 6).
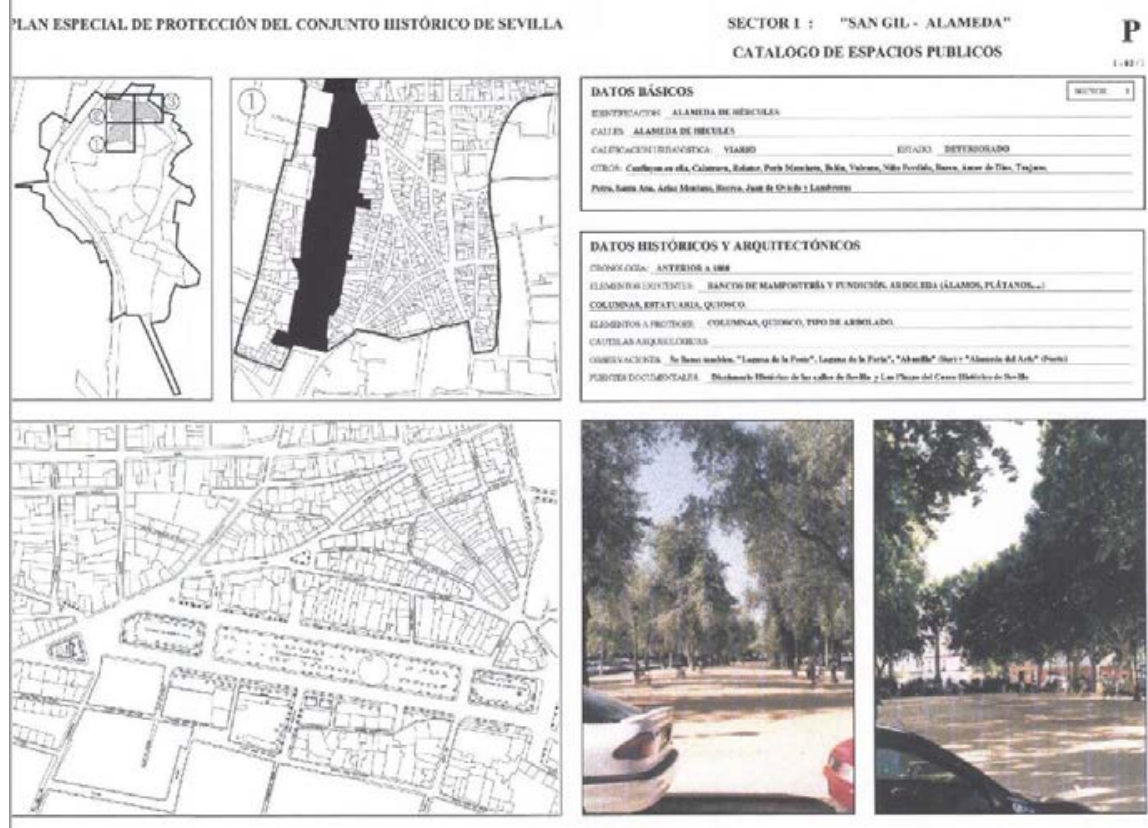

Fuente: Ayuntamiento de Sevilla

Fig. 6 Ficha de catalogación como Espacio Público en el Plan Especial del Sector 1 del Conjunto Histórico de Sevilla "San Gil - Alameda" 


\section{Resultados y conclusiones}

En primer lugar es preciso destacar que en la ciudad histórica, el espacio público no ocupaba la posición relevante que adquiere desde el siglo XX bajo los postulados del Movimiento Moderno.

A partir de lo anterior, la implantación de alamedas con un diseño de forma alargada, una hilera de árboles y un remate circoagonal en sus extremos, sería una forma de ordenación espacial de las ciudades, pero también una medida de sociabilidad pública ya no solo restringida a los jardines privados. Es así como la Alameda de Hércules en el siglo XVI nace en los intramuros de la ciudad de Sevilla, situada hacia el noroeste. Esta es singular por diferenciarse de otras que surgieron extramuros y porque dio regularidad espacial a la zona en que se emplazó, derivado de un desecamiento producido por las inundaciones del río Guadalquivir.

Como transferencia tipológica de su diseño es posible señalar que sería el Marqués de Montesclaros, quien como sucesor del Conde de Barajas y asistente de la ciudad de Sevilla, conocía la Alameda de Hércules cuando se instaló en la América española. De este modo, la realidad de la Alameda de los Descalzos de Lima en un área periférica tendría claros indicios de ser una réplica de la Alameda de Sevilla. Al mismo tiempo, algunos plantean que la Alameda de México también se basó en la hispalense. Sin embargo, habría que considerar un cambio importante en su forma, pasando de una figura lineal alargada como la sevillana a una de superficie rectangular con diagonales en el caso mexicano.

Bajo esta perspectiva, en la actualidad, la Alameda de Hércules está caracterizada por ser un espacio contenido y con elementos característicos en su configuración espacial: arbolado, explanada y arquitectura. Esta última restringida a las fachadas que están en torno a la Alameda. No obstante, su forma y emplazamiento original se ha visto desdibujado pasando a ser una suerte de explanada en la que se acogen las actividades recreativas y sociales de diversa naturaleza, erigiéndose y recuperándose hoy como un espacio de destacada concurrencia y que, podríamos decir, representa un lugar de ocio y sociabilidad para el Centro Histórico de la ciudad.

Por tanto, la Alameda de Hércules actualmente cumple una función más allá del paseo y la circulación, objetivo de su creación intramuros, siendo también un lugar importante para la permanencia del viandante. De este modo cabría preguntarse por qué estas cualidades no se han puesto de relieve en el planeamiento urbano y paísajístico de la ciudad de Sevilla. Resulta llamativa la menor atención en el reconocimiento y protección patrimonial que suscita este espacio público, algo que se ve agudizado al compararlo con el caso de los edificios patrimoniales. Es conveniente establecer un vínculo entre la arquitectura patrimonial y determinados espacios públicos que la circundan, en un claro objetivo de relevar la importancia de la aparición del verde urbano al interior de las ciudades amuralladas del siglo XVI, considerando la situación en la que surge la Alameda de Hércules.

En definitiva, el revisar el devenir histórico de la Alameda, más allá del siglo XVI, también permite comprender su adaptabilidad a las distintas casuísticas y necesidades de la sociedad hasta la actualidad, incorporándola en este proceso como patrimonio contemporáneo. Por lo tanto, el diseño de tres calles, siendo la central más amplia, delimitada por árboles y con las dos columnas de pórtico de acceso, de Hércules y Julio César, la convertirían en una explanada de uso intensivo.

Ante todo este recorrido en el mayor conocimiento de la Alameda como elemento patrimonial, queda hacernos algunas preguntas: ¿podría plantearse un mayor reconocimiento patrimonial a la Alameda de Hércules? ¿no sería pertinente abogar por su protección como Jardín Histórico con arreglo a la Ley 14/2007 del Patrimonio Histórico de Andalucía? ¿incluso, dada su relevancia tipológica y su influencia como generadora de otros ejemplos internacionales, podría proponerse como Patrimonio Mundial?

\section{Referencias}

Albardonedo Freire, A. J. (1998). Las trazas y construcción de la Alameda de Hércules. Laboratorio de Arte, 11, 135-165.

Ayuntamiento de Sevilla. (2002). Plan Especial de Protección Sector 1: San Gil-Alameda. Sevilla: Ayuntamiento de Sevilla.

Biblioteca Nacional de España. (n. d.). Plano de los paseos del Prado, Recoletos y Atocha de Madrid. Recuperado de www.bne.es 
Bibliothèque nationale de France. (2016). Plan de la Ville de Lima, au Perou. Recuperado de http://catalogue.bnf.fr/ark:/12148/ $\underline{\mathrm{cb} 44307821 \mathrm{~d}}$

Chueca Goitia, F. (1954). La época de los Borbones. En A. García y Bellido, L. Torres Balbas, L. Cervera, F. Chueca y P. Bidagor (Eds.), Resumen Histórico del Urbanismo en España (pp. 149-187). Madrid: Instituto de Estudios de Administración Local.

Durán Montero, M. A. (1985). La Alameda de los Descalzos de Lima y su relación con las de Hércules de Sevilla y la del Prado de Valladolid. En B. Torres Ramíez y J. Hernández Palomo (Eds.), Actas III Jornadas de Andalucía y América (pp. 171-182). Sevilla: Escuela de Estudios Hispanos-Americanos.

Gerencia de Urbanismo de Sevilla (2017). BIC Sevilla. Recuperado de https://sig.urbanismosevilla.org/jsapi/ideS/SocialMediaViewer/ index_BIC.html?webmap=e18ed1ee72694170bd0788245c70f57a\&showAboutDialogOnLoad=true

Gobierno de España (n. d.). Alameda de Hércules de Sevilla en 1574 en la Red Digital de Colecciones de Museos de España. Recuperado de http://ceres.mcu.es/pages/SimpleSearch?index=true $(20 / 11 / 2019)$

Junta de Andalucía (2007). Ley 14/2007, de 26 de noviembre, del Patrimonio Histórico de Andalucía. En BOJA, núm. 248 , de 19 de diciembre de 2007 (pp. 6-28). Sevilla: Junta de Andalucía.

Junta de Andalucía (n. d.). Catálogo General del Patrimonio Histórico Andaluz. Recuperado de https://www.juntadeandalucia.es/ organismos/culturaypatrimoniohistorico/areas/bienes-culturales/catalogo-pha/consulta.html (20/11/2019)

León Vela, J. (2000). La Alameda de Hércules y el centro urbano de Sevilla: hacia un reequilibrio del casco antiguo. Colección Arquitectura. Sevilla: Universidad de Sevilla.

Lopezosa Aparicio, C. (2016). Los paseos en las ciudades iberoamericanas del setecientos. Análisis de su inserción urbana y su repercusión en el contexto de las urbes. En E. Giannotti, R. Booth y A. Peliowski (Eds.), Actas I Congreso Iberoamericano de Historia Urbana: Ciudades en el tiempo: infraestructuras, territorio, patrimonio. Santiago de Chile: Asociación Iberoamericana de Historia Urbana.

Luque Azcona, E. J. (2015). Conformación y características de las alamedas y paseos en ciudades de Hispanoamérica. Anuario de Estudios Americanos, 2(72), 487-513.

Nieto Caldeiro, S. (1991). El jardin sevillano de 1900 a 1929. Tesis doctoral. Madrid: Universidad Complutense.

Ollero, F. (2015). Ciudad e llustración. Transformaciones urbanas en Sevilla (1767-1823). Cuadernos dieciochistas 16, $215-257$.

Olavide, P. (1771). Plano de la ciudad de Sevilla. En J. Cortés José, M. J. García Jaén y F. Zoido Naranjo (Coords.), Planos de Sevilla. Colección Histórica (1771-1918). Sevilla: Servicio de Publicaciones del Ayuntamiento de Sevilla y Editorial MAD S.L.

Paya, L. (2014). Les alamédas d l'empire espagnol durant la Renissance: un ensemble singulier et cohérent de promenades arborées. Le Verger-bouquet, 5, 1-19.

Torres García, M. (2019). La alameda de Hércules de Sevilla. Evolución de formas y usos. En A. Collantes de Terán, R. Gutiérrez, A. J. Albardonedo, S. Carazo, M. Fernández, J. Jiménez, A. Moreno, P. Nieto y M. Torres (Eds.), Las alamedas. Elemento urbano y función social en ciudades españolas y americanas (pp. 265-295). Barcelona: Ediciones del Serbal.

Vioque, R., Vera, I., y López, N. (1987). Apuntes sobre el origen y evolución morfológica de las Plazas del Casco Histórico de Sevilla. Sevilla: Consejería de Obras Públicas y Transportes. 